NASA/CR-1999-208871

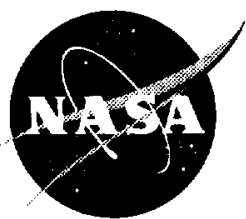

\title{
Passively Damped Laminated Piezoelectric Shell Structures With Integrated Electric Networks
}

Dimitris A. Saravanos

Ohio Aerospace Institute, Cleveland, Ohio

Prepared under Cooperative Agreement NCC3-455

National Aeronautics and

Space Administration

Glenn Research Center 


\section{Acknowledgments}

This work was performed at the Machine Dynamics Branch, Structures and Acoustics Division of NASA Glenn Research Center and was funded by NASA cooperative agreement NCC3-455.

Mr. Dale A. Hopkins was the contract monitor. This support is gratefully acknowledged.

This report is a preprint of a paper intended for presentation at a conference. Because of changes that may be made before formal publication, this preprint is made available with the understanding that it will not be cited or reproduced without the permission of the author.

Available from

NASA Center for Aerospace Information

7121 Standard Drive

Hanover, MD 21076

Price Code: A03
National Technical Information Service 5285 Port Royal Road Springfield, VA 22100

Price Code: A03 


\title{
PASSIVELY DAMPED LAMINATED PIEZOELECTRIC SHELL STRUCTURES WITH INTEGRATED ELECTRIC NETWORKS
}

\author{
Dimitris A. Saravanos* \\ Ohio Aerospace Institute \\ 22800 Cedar Point Road \\ Cleveland, Ohio 44142
}

\begin{abstract}
SUMMARY
Multifield mechanics are presented for curvilinear piezoelectric laminates interfaced with distributed passive electric components. The equations of motion for laminated piezoelectric shell structures with embedded passive electric networks are directly formulated and solved using a finite element methodology. The modal damping and frequencies of the piezoelectric shell are calculated from the poles of the system. Experimental and numerical results are presented for the modal damping and frequency of composite beams with a resistively shunted piezoceramic patch. The modal damping and frequency of plates, cylindrical shells and cylindrical composite blades with piezoelectric-resistor layers are predicted. Both analytical and experimental studies illustrate a unique dependence of modal damping and frequencies on the shunting resistance and show the effect of structural shape and curvature on piezoelectric damping.
\end{abstract}

\section{INTRODUCTION}

The continuous requirements imposed on many new structural applications for improved vibroacoustic response and weight reduction mandate the development of new damping concepts. Embedded piezoelectric layers introduce the unique capability to convert strain energy to electric energy during a vibration cycle and vice-versa. By connecting passive electric networks of resistors and capacitors to the piezoelectric layers, a fraction of electric energy may be dissipated or spontaneously stored, thus increasing the damping and changing the natural frequencies of the structure. Compared to other techniques which typically introduce high damping, for example, the constrained interlaminar viscoelastic layer and active damping techniques, the passive piezoelectric damping may exhibit very desirable characteristics, such as: capability to be modified, spontaneously or periodically, by varying the properties of the passive electric elements (resistors, capacitors, etc.); damping improvement may not decrease laminate stiffness, as is the case with viscoelastic damping layers; and the required hardware is minimal and may be even encapsulated into the laminate, thus adding minimal weight to the structure. Consequently, the approach may be very suitable for damping vibrations in rotating or moving components, such as turbomachinery blades, helicopter blades, and so forth.

While substantial work has been reported in the area of active vibration control as described in recent reviews (refs. 1 to 2), most of the reported work on passive piezoelectric damping has been limited to simple laminate and structural (mostly beam and plate) configurations. Hagood and Von Flotow (ref. 3) first studied analytically and experimentally the use of passive piezoelectric elements to dampen beam structures. Law et al. (ref. 4) have reported simplified models and experimental results for piezoelectric materials shunted by a load resistor. Davis and Lesieutre (ref. 5) predicted the passive damping of beams with resistively shunted piezoelectric patches based on the strain energy dissipation approach, and reported experimental results. Koshigoe and Murdock (ref. 6) reported a simplified analytical formulation for plates with passive piezoelectric elements. Wang et al. (ref. 7) have reported work on a semi-active vibration control approach for beams with piezoelectric elements combining passive electric components with an active controller concept. Yarlagadda et al. (ref. 8) presented micromechanics and experimental results for composites with resistively shunted piezoceramic fibers. Saravanos (ref. 9) developed an exact in-plane Ritz formulation for the prediction of damping in composite plates with resistively shunted piezoelectric elements.

Senior Research Associate. 
While the reported work has provided valuable insight regarding the potential of passive piezoelectric damping, development of efficient methodologies enabling the prediction of damping in realistic laminate and structural configurations is still required. This paper presents multi-field mechanics for curvilinear composite laminates with piezoclectric layers having distributed passive electric components embedded or attached to the piezoelectric layers, and an associated shell finite element for predicting the modal damping, modal frequencies and dynamic response of damped piezoelectric shells. The laminate mechanics combine single-layer kinematic assumptions for the displacements with a layerwise variation of the electric potential. The formulation directly considers the presence of distributed electric networks, thus enabling coupled and efficient representations of the integrated laminate-electric circuit system. Governing equations of motion are developed and solved in state-space form. The poles of the coupled structural system are calculated and used to evaluate the modal damping and frequencies of the shell structure. The frequency response of the damped structure is also directly calculated from the equations of motion.

\section{DOUBLY CURVED PIEZOLAMINATES WITH PASSIVE ELECTRIC NETWORKS}

The curvilinear laminate configuration with attached distributed electric components and piezoelectric actuators is shown schematically in figure 1(a). It is assumed that each ply of the laminate remains parallel to a reference curvilinear surface $A_{O}$ which is defined with respect to a global Cartesian coordinate system Oxyz. An orthogonal curvilinear coordinate system $\overline{0} \xi \eta \zeta$ is defined, such that the axes $\xi$ and $\eta$ lie on the curvilinear reference surface $A_{\theta}$, while the axis $\zeta$ remains straight and perpendicular to the layers of the laminate. A series of resistor-capacitor circuits may be connected to piezoelectric layers.

Governing material equations.-Each ply is assumed to be a linear piezoelectric material with properties defined on the orthogonal curvilinear system $\overline{0} \xi \eta \zeta$, and constitutive equations of the following form,

$$
\begin{gathered}
\sigma_{i}=C_{i j}^{E} S_{j}-e_{i k} E_{k} \\
D_{l}=e_{l j} S_{j}+\varepsilon_{l k}^{S} E_{k}
\end{gathered}
$$

where: $i, j=1, \ldots, 6$ and $k, l=1, \ldots, 3 ; \sigma_{i}$ and $S_{i}$ are the mechanical stresses and engineering strains in vectorial notation; $E_{k}$ is the electric field vector; $D_{l}$ is the electric displacement vector; $C_{i j}$ is the elastic compliance and stiffness tensors; $e_{l j}$ is the piezoelectric tensor; and $\varepsilon_{l k}$ is the electric permittivity tensor of the material. Superscripts $E$ and $S$ indicate constant electric field and strain conditions, respectively. The axes 1,2, and 3 of the material are parallel to the curvilinear axes $\xi$, $\eta$, and $\zeta$. The materials are assumed to be monoclinic class 2 crystals with a diad axis (polarization direction) parallel to the $\zeta$ axis. The tensorial strain $S_{i j}$ and electric field components in a curvilinear coordinate system are related to the displacements and electric potential. The strain-displacement relationships and the relation of the electric field vector $E_{k}$ to the electric potential $\phi$ are provided in reference 10 .

Laminate theory.-The mixed-field laminate theory (ref. 10) is extended here to address the case of piezoelectric laminates with distributed electric circuitry (fig. 1(b)). The theory combines linear displacement fields through the thickness of the laminate for the displacements $u, v$ (along the $\xi$ and $\eta$ axes respectively) with a layerwise electric potential field through the laminate, consisting of $\mathrm{N}$ discrete continuous segments (fig. 1(c)). By assuming different approximations for each field, the method retains efficiency for thin and intermediate thick laminates, while the representation of multiple fields and piezoelectric coupling is maintained. The discrete layer assumption effectively subdivides the laminate into $\mathrm{N}-1$ sublaminates (or discrete-layers). The grade of subdivision can be arbitrarily controlled according to the configuration of the piezoelectric layers and/or the required detail of approximation. A continuous electric potential is assumed in each sublaminate, such that a $C_{0}$ continuous variation results through the thickness of the laminate. The displacements and electric potential take the following form,

$$
\begin{aligned}
u(\xi, \eta, \zeta, t) & =u^{o}(\xi, \eta, t)+\zeta \beta_{\xi}(\xi, \eta, t) \\
v(\xi, \eta, \zeta, t) & =v^{o}(\xi, \eta, t)+\zeta \beta_{\eta}(\xi, \eta, t) \\
w(\xi, \eta, \zeta, t) & =w^{\prime \prime}(\xi, \eta, t) \\
\phi(\xi, \eta, \zeta, t) & =\sum_{j=1}^{N} \phi^{j}(\xi, \eta, t)+\Psi^{j}(\zeta)
\end{aligned}
$$


where $u^{\prime}, v^{\prime \prime}, w^{\prime \prime}$ are displacements along the $\xi, \eta$ and $\zeta$ axes, respectively, on the reference surface $A_{\theta}$; superscript $j$ indicates the points $\xi^{j}$ at the beginning and end of each discrete layer; $\phi^{j}$ is the electric potential at each point $\zeta^{j}$ (see fig. 1(c)); $\psi^{j}(z)$ are interpolation functions; and $\beta_{\xi}, \beta_{\eta}$ are the rotation angles.

$$
\beta_{\xi}=-\frac{w_{\cdot \xi}^{o}}{g_{11}^{\prime \prime}}+\frac{u^{o}}{R_{1}}, \quad \beta_{\eta}=-\frac{w_{. \eta}^{\prime \prime}}{g_{22}^{\prime \prime}}+\frac{v^{\prime \prime}}{R 2}
$$

where $R_{i}$ are the local radii of curvature (fig. 1(a)); $g_{11}^{o}, g_{22}^{o}$ are the components of the metric tensor for the reference surface.

Equations of motion.- The variational statement of the equations of motion for a piezoelectric laminate with assumed displacement and electric potential fields takes the form (ref. 10):

$$
\int_{A_{o}}-\left(\delta H_{L}(S, E)-\delta T_{L}\right) d \xi d \eta+\oint_{\Gamma_{\tau}} \delta u_{i}^{T} \bar{\tau}_{i} d \Gamma+\oint_{\Gamma_{\phi}} \delta \phi \bar{D} d \Gamma=0
$$

where $A_{o}$ is the curvilinear reference surface, $\tau$ and $D$ overbar are the surface tractions and electric displacement acting respectively on boundary surfaces $\Gamma_{\tau}, \Gamma_{\phi} ; \delta H_{L}$ and $\delta T_{L}$ are the variations of the electric enthalpy and kinetic energy of the laminate, defined as,

$$
\left\langle\delta H_{L}, \delta T_{L}\right\rangle=\int_{0}^{h}\langle\delta H, \delta T\rangle g_{11}^{\prime \prime} g_{22}^{\prime \prime} d \zeta
$$

and $h$ is the laminate thickness. The electric enthalpy of the piezoelectric laminate is a quadratic expression of the generalized strain/electric field and the generalized laminate matrices (ref. 10),

$$
\begin{array}{r}
\delta H_{L}=\delta S_{i}^{\prime} A_{i j} S_{j}^{\prime \prime}+\delta S_{j}^{o} B_{i j} k_{j}+\delta k_{j} B_{j i} S_{i}^{o}+\delta k_{i} D_{i j} k_{j}-\sum_{m=1}^{N}\left(\delta S_{i}^{o} \bar{E}_{i k}^{m} E_{k}^{m}+\delta E_{k}^{m} \bar{E}_{k i}^{m} S_{i}^{\prime \prime}+\delta k_{j} \hat{E}_{j}^{m} E_{3}^{m}+\delta E_{3}^{m} \hat{E}_{j}^{m} k_{j}\right) \\
-\sum_{i=1}^{N} \sum_{i=1}^{N} \delta E_{k}^{m !} \mathrm{G}_{k l}^{m n} E_{l}^{m}
\end{array}
$$

In the above equation, $[A],[B]$, and $[D]$ are the stiffness matrices of the curvilinear laminate, $\left[E^{m}\right]$ overbar and overhat are the piezoelectric matrices, and $\left[G^{m m}\right]$ are the laminate matrices of electric permittivity. $L$ is the number of plies in the laminate. The kinetic energy of the laminate takes the form,

$$
\delta T_{L}=\delta u_{i}^{o} \rho_{i}^{A} u_{i}^{o}+\delta u_{j}^{o} \rho_{j}^{B} \dot{\beta}_{j}+\delta \beta_{j} \rho_{j}^{B} \dot{u}_{j}+\delta \beta_{j} \rho_{j}^{D} \dot{\beta}_{j}, \quad i=1, \ldots, 3, j=1,2
$$

where $u_{i}^{o}=\left\{u^{o}, v^{o}, w^{o}\right\}$ and $\beta_{i}=\left\{\beta_{\xi}, \beta_{\eta}\right\} ; \rho^{A}, \rho^{B}, \rho^{D}$ are the generalized densities, expressing the mass, mass coupling and rotational inertia per unit area, respectively, of the laminate.

Electric circuitry.-Considering that a passive electric circuit with resistive and capacitive elements is interfaced to the terminal surfaces $m$ and $n$ (see fig. 1(b)) of the piezoelectric laminate, the electric potential $f$ and electric flux $\phi$ in the circuit are related as follows,

$$
\left\{\begin{array}{l}
J^{m} \\
J^{n}
\end{array}\right\}=\left[\begin{array}{cc}
c & -c \\
-c & c
\end{array}\right]\left\{\begin{array}{l}
\dot{\phi}^{m} \\
\dot{\phi}^{n}
\end{array}\right\}+\left[\begin{array}{cc}
r^{-1} & -r^{-1} \\
-r^{-1} & r^{-1}
\end{array}\right]\left\{\begin{array}{l}
\phi^{m} \\
\phi^{n}
\end{array}\right\}
$$


where $r^{-1}$ and $c$ are the inverse resistance and capacity per unit area of the laminate. Considering the more general case of multiple passive networks attached at various thickness locations, the equilibrium equations are expressed in similar matrix form.

$$
\left.\left\{J^{p}(t)\right\}=\mid c\right]\left\{\dot{\phi}^{p}(t)\right\}+\left[r^{-1}\right]\left\{\phi^{p}(t)\right\}
$$

where $p$ indicates passive circuits and the specific capacitance and resistance matrices are formulated in accordance with equation (8) and include contributions of all laminate circuits.

Compatibility conditions.-At the $j$ common terminal between the piezoelectric laminate and the electric circuit, the electric potential at the laminate should be equal to the electric potential of the circuit, and the electric flux in the electric circuit should be equal to the rate of the generalized normal electric displacement.

$$
\phi_{L}^{j}=\phi_{p}^{j}, \quad J_{p}^{j}=\dot{D}_{3 L}^{j}
$$

where subscripts $L$ and $p$ indicate the laminate and passive circuit respectively.

\section{PASSIVE PIEZOELECTRIC SHELL STRUCTURES}

A finite element based method is developed using the previous laminate mechanics for predicting the dynamic characteristics and response of shell structures having piezoelectric layers or patches attached to passive electric circuits. The FEM uses approximations of the generalized electromechanical state (displacements, rotation angles and electric potential) on the reference surface $A_{i}$, of the following type,

$$
\begin{aligned}
u_{j}^{o}(\xi, \eta, t) & =\sum_{i=1}^{M} u_{j}^{o i}(t) N^{i}(\xi, \eta), \quad j=1, \ldots, 3 \\
\beta_{j}(\xi, \eta, t) & =\sum_{i=1}^{M} \beta_{j}^{i}(t) N^{i}(\xi, \eta), \quad j=1,2 \\
\phi^{m}(\xi, \eta, t) & =\sum_{i=1}^{M} \phi^{m i}(t) N^{i}(\xi, \eta), \quad m=1, \ldots, N
\end{aligned}
$$

where superscript $i$ indicates the reference surface displacement, rotation angle and generalized electric potential components corresponding to the $\mathrm{i}$-th in-plane interpolation function $N^{i}(\xi, \eta)$. An 8-node quadrilateral curvilinear element was considered in this work. Selective reduced integration is used for the calculation of shear and piezoelectric stiffness terms to overcome spurious stiffening observed at low thicknesses. Substituting into the generalized equations of motion (4), and collecting the coefficients as mandated by equations (6) and (7), the governing dynamic equations of the structure and the distributed electric circuitry are expressed in discrete matrix forms.

Piezoelectric structure.-Considering an active-passive piezoelectric structure containing piezoelectric layers connected to passive circuitry and piezoelectric actuators, the electric potential vector can be subdivided in a passive component $\phi^{\prime \prime}$ representing the electric potential at passive piezoelectric layers, and an active component $\phi^{A}$ representing the potential imposed on the actuator nodes, such that $\{\phi\}=\left\{\phi^{p} ; \phi^{A}\right\}$. The partitioned system takes the form,

$$
\left[\begin{array}{cc}
{\left[M_{u u t}\right]} & 0 \\
0 & 0
\end{array}\right]\left\{\begin{array}{c}
\{u\} \\
\left.\ddot{\phi}^{p}\right\}
\end{array}\right\}+\left[\begin{array}{cc}
{\left[K_{u u t}\right]} & {\left[K_{u \phi}^{P P}\right]} \\
{\left[K_{\phi u}^{P P}\right]} & {\left[K_{\phi \phi}^{P P}\right]}
\end{array}\right]\left\{\left\{\begin{array}{c}
\{u\} \\
\left\{\phi^{p}\right\}
\end{array}\right\}=\left\{\begin{array}{c}
\{F(t)\}-\left[K_{u \phi}^{P A}\right]\left[\phi^{A}\right\} \\
\left\{Q^{P}(t)\right\}-\left[K_{\phi \phi}^{P A}\right]\left\{\phi^{A}\right\}
\end{array}\right\}\right.
$$

with $N_{s}$ unknown displacements $\{u\}$, and $N_{p}$ unknown electric potentials $\left\{\phi^{P}\right\}$. The presence of continuous electrodes is considered in the previous equation by imposing equality constraints on the nodal electric potential of the electrode surface by means of the penalty method. 
Electric circuitry.-The applied electric displacement term in equation (4) can be rewritten considering the second compatibility equation (10),

$$
\int_{\Gamma_{\phi}} \delta \phi \dot{D} d \Gamma=\int_{\Gamma_{\phi}} \delta \phi J d \Gamma
$$

Combination of equation (13) with equation (9) and application of the layerwise and finite element approximation of electric potential yields the discretized compatibility equation for the electric flux between the piezoelectric layers and passive electric circuitry

$$
\left\{\dot{Q}^{p}(t)\right\}=\left\{I^{p}(t)\right\}=[C]\left\{\dot{\phi}^{p}(t)\right\}+\left[R^{-1}\right]\left\{\phi^{p}(t)\right\}
$$

where $Q^{P}, I^{P}$ are the electric charge and current, respectively, at the interface nodes. $[C]$ and $\left[R^{-1}\right]$ are the capacitance and inverse resistance submatrices of the distributed electric system, between nodes $i, j$ of the finite element,

$$
\begin{aligned}
{\left[R^{-1}\right]^{i j} } & =\int_{A_{u \psi}}\left[N^{i}\right]^{T}\left[r^{-1}\right]\left[N^{j}\right] g_{11}^{\prime \prime} g_{22}^{o} d \xi d \eta \\
{[C]^{i j} } & =\int_{A_{v e}}\left[N^{i}\right]^{T}[c]\left[N^{j}\right] g_{11}^{o} g_{22}^{\prime \prime} d \xi d \eta
\end{aligned}
$$

Combined structural system.- Combining the equations of motion for the piezoelectric shell (ref. 12) with the compatibility equation (14) for the distributed electric system, the governing equations of the combined system result in state space form. The left-hand side includes the unknown electromechanical state $\left\{V ; U ; \Phi^{\prime}\right\}$ which contains the velocities, displacements, the electric potential at the common terminals of the passive piezoelectric layers. The right-hand side includes the excitation of the plate in terms of mechanical loads and applied voltages on the actuators:

$$
\left[\begin{array}{ccc}
{\left[M_{u u}\right]} & 0 & 0 \\
0 & I & 0 \\
0 & 0 & {\left[K_{\phi \phi}^{P P}\right]-[C]}
\end{array}\right]\left\{\begin{array}{c}
\{\dot{V}\} \\
\{\dot{U}\} \\
\left\{\dot{\Phi}^{p}\right\}
\end{array}\right\}=\left[\begin{array}{ccc}
0 & -\left[K_{u u}\right] & -\left[K_{u \phi \phi}^{P P}\right] \\
I & 0 & 0 \\
{\left[-K_{\phi u}^{P P}\right]} & 0 & {\left[R^{-1}\right]}
\end{array}\right]\left\{\begin{array}{c}
\{V\} \\
\{U\} \\
\left\{\Phi^{p}\right\}
\end{array}\right\}+\left\{\begin{array}{c}
\left.\{F(t)\}-\left[K_{u \phi}^{P A}\right]\right]\left\{\Phi^{A}\right\} \\
0 \\
0
\end{array}\right\}
$$

The capacitance $[C]$ of the electric circuit is added to the internal çapacitance of the passive piezoelectric layers. The electric resistance appears to be the only damping mechanism, since no other sources of damping are considered in the present study. This dynamic system is solved to provide either the free vibration, or the frequency response of the damped structure.

Modal characteristics.-Assuming free vibration conditions with state variables of the form $\left\{U(t), V(t), \Phi^{P}(t)\right\}$ $=\left\{U, V, \Phi^{P}(t)\right\} \mathrm{e}^{\mathrm{st}}, 2 N_{s}+N_{p}$ complex eigenvalues (poles) are calculated from equation (16). The $2 N_{s}$ poles are conjugate complex pairs $s_{k}{ }^{*}$ corresponding to the vibration modes. The remaining $N_{p}$ eigenvalues are negative real numbers corresponding to time constants of the electric circuitry. The modal frequency and damping ratio of the structural modes is directly calculated from the poles,

$$
\omega_{k}=\left\|s_{k}^{*}\right\|, \quad \zeta_{k}=\operatorname{Re}\left(s_{k}^{*}\right) / \omega_{k}
$$

Frequency response.-Assuming harmonic state variables $\left\{U(t), V(t), \Phi^{P}(t)\right\}=\left\{U, V, \Phi^{P}\right\} \mathrm{e}^{\mathrm{j} \omega t}$, force $\mathrm{Fe} \mathrm{e}^{\mathrm{j} \omega t}$ and applied electric potential $\Phi^{A} \mathrm{e}^{\mathrm{j} \omega t}$, equation (16) provides a linear system of equations with complex coefficients. Solution of the system yields the response $\left\{U, V, \Phi^{P}\right\}$ of the structure at frequency $\omega$. 


\section{CASE STUDIES}

Various numerical studies were performed in order to evaluate the accuracy and convergence of the developed formulation, including: (1) comparisons with measured damping and frequency data of composite beams with an attached piezoceramic-resistor patch, and (2) convergence studies towards exact Ritz in-plane solutions for specialty plates and cylindrical panels with distributed piezoelectric-resistor layers. The piezoelectric damping of clampedfree cylindrical composite blades with discrete piezoelectric-resistor patches was also investigated.

Materials and assumptions.-The properties of all materials are shown in table I. The T300/934 Graphite/epoxy composite was used for all composite laminates in this work. Composite beam specimens of this material were also fabricated and tested. A PZT-4 piezoceramic was considered in all numerical examples. PZT-4 patches provided by American Piezoceramics International (material APC 840) were used in the fabrication of the beam specimens.

$10_{4} 490_{4} 1_{\Sigma}$ Cantilever beam. - A $\left[0_{4} / 90_{4}\right]_{\mathrm{s}} \mathrm{T} 300 / 934 \mathrm{Graphite} /$ Epoxy beam, $234 \mathrm{~mm}$ long and $25.4 \mathrm{~mm}$ wide, with a surface epoxied PZT-4 patch having a variable resistor attached on its surface terminals was fabricated and tested. The beam was supported in cantilever configuration, and the modal characteristics were measured and also predicted using the developed shell finite element. Figure 2 shows the geometry and testing configuration of the beam. The direction of fibers in the $0^{\circ}$ plies was parallel to the beam axis, the thickness of each composite ply was $0.262 \mathrm{~mm}$, while the thickness of the piezoceramic patch was $0.762 \mathrm{~mm}$. The size of the piezoceramic patch was 50.8 by $25.4 \mathrm{~mm}$, and the lower electrode was wrapped around the free-edge and covered $2 \mathrm{~mm}$ of the upper surface to provide space for wiring (see fig. 2 ).

The beam was impacted with an instrumented hammer and the acceleration was measured using a $0.50 \mathrm{gr}$ accelerometer, at the location shown in figure 2 . The electric signals from the impact hammer and accelerometer were acquired and digitized using a PC based dynamic data acquisition card and software. The frequency response functions were calculated from the impact response data using FFT software. The poles of the beam were subsequently estimated using the method of complex exponentials. A model transfer function consisting of a series of conjugate pairs of complex exponential terms (each pair corresponding to a mode) was correlated to the measured frequency response function until the least-squares error was minimized. The modal frequency and damping were subsequently calculated from the poles of the model system and they were assumed to approximate closely the modal damping and frequency values of the tested beam. After each measurement, the resistance was varied and measured, and the test was repeated.

The measured damping increment and natural frequency of the first mode of the beam for various resistance values are shown in figures 3 and 4 . The damping increment was calculated from the measured damping at resistance $R$ by substracting the measured damping at open circuit conditions $(R=\infty)$ which was considered to represent the baseline damping of the beam. The same figures also show the predicted values using a $14 \times 1$ nonuniform mesh of the shell finite element. The presence of continuous electrodes was also modeled. The mass of the accelerometer was found to affect the dynamics of the beam and was included into the finite element model. Both measured and predicted damping and frequency values follow the same trends and are within reasonable agreement. The finite element predictions seem to overestimate the measured data. The lower measured values are attributed to the presence and compliance of the adhesive layer (whereas the present formulation assumes a perfect bond) and possible degradation of the actual piezoelectric coefficients than the ones provided by the manufacturer and used in the model.

Figures 3 and 4 illustrate that there is an optimal resistance where damping reaches a maximum and frequency shifts to a higher value. Beyond this optimal resistance value, the resistor and the capacitance of the piezoelectric layer effectively form a low-pass filter on the electric current flowing through the resistor. The cut-off frequency is related to the resistance and capacitance of the piezoelectric layers. When the cut-off frequency exceeds the frequency of a specific vibration mode, the electric flux through the resistor decreases and a fraction of electric flux is stored in the piezoelectric capacitor during a vibration cycle. This decreases the dissipation of electric energy at the resistor. and thus lowers the damping. As the bulk of electric energy remains stored in the piezoelectric capacitor, the elastic strain energy of the beam is reduced resulting in higher natural frequencies.

Simply supported plate.-A simply supported [p/0/90/90/0/p] cross-ply Graphite/Epoxy composite square plate is considered, with surface attached distributed piezoceramic (PZT-4) layers grounded at the inner surface and each shunted with equal distributed resistance per unit area $r$. The nominal thickness of each composite ply was $t_{l}=0.375 \mathrm{~mm}$ and of each piezoelectric layer was $t_{p}=0.250 \mathrm{~mm}$, thus, resulting in total plate thickness $h=2 \mathrm{~mm}$. 
The free length of the plate along the $\mathrm{x}$ and $\mathrm{y}$ axes was $L_{x} / h=L_{\mathrm{V}} / h=157$. Considering the two planes of symmetry, only a quarter of the plate was modeled using a uniform mesh. Figure 5 shows the damping and natural frequency predictions of the fundamental mode using various mesh densities, together with an exact in-plane Ritz solution based on the same laminate assumptions (ref. 9). Both damping and natural frequency predictions converge rapidly to the exact in-plane solution. As in the previous example, there is an optimal resistance where damping reaches a maximum and frequency shifts to a higher value. Figure 6 shows the damping of additional modes evaluated using a $6 \times 6$ uniform mesh. Besides the good agreement between the FE and exact solution, the results show that as the modal frequency increases the corresponding damping peak occurs at lower resistance.

Simply-supported cylindrical panel.--The simply supported cylindrical quarter panel shown in figure 7 is considered. The panel has identical $\mathrm{Gr} / \mathrm{Epoxy}[\mathrm{p} / 0 / 90]_{\mathrm{S}}$ laminate configuration, ply thicknesses and materials with the previous case, with the $0^{\circ}$ plies aligned along the hoop direction. Each PZT-4 layer is shunted with a distributed resistance per unit area $r$. The length of the panel along the hoop $(\xi)$ and axial $(\eta)$ axes is $L_{\xi} / h=L_{\eta} / h=157$. Taking into consideration the symmetry in axial direction, only one-half of the panel was modeled using a uniform mesh.

Figure 8 shows the damping and frequency of the first mode which in this case is mode $(3,1)$. The numbers in parenthesis indicate the wavelengths along the hoop $(\xi)$ and axial $(\eta)$ direction. Both damping and frequency predictions seem to rapidly converge towards an exact in-plane solution, although higher element subdivisions are required along the circumferential direction. Figure 9 shows the predicted damping and frequency corresponding to mode shape $(1,1)$ which occurs at a higher natural frequency, as a result of stiffening from extension-bending coupling introduced by the curvature. The finite element predictions seem to converge to slightly different values from the Ritz solution. Figure 10 shows damping predictions for the first 5 modes, and the very good overall agreement between a 16×4 FE mesh and an in-plane exact Ritz method developed by the author. All modes illustrate the familiar pattern of a maximum damping peak and shifting in the natural frequency with increasing resistance values. However, the prevailing difference with the previous plate case is the wide variation between the damping peaks of the various modes, with modes $(1,1)$ and $(3,1)$ having the lower and higher damping peak, respectively. Curvature induced extension-flexure coupling seems to adversely affect the damping effectiveness of the piezoelectric layers. as it reduces the flexural strain-energy stored and dissipated at the piezoelectric layers. Overall, the present and previous cases have demonstrated the accuracy and convergence rate of the developed approach.

\section{CANTILEVER CYLINDRICAL PANEL WITH PIEZOELECTRIC PATCHES}

The more realistic case of a [0/90/45/-45 $]_{\mathrm{S}}$ Graphite/Epoxy cylindrical quarter-panel having curved PZT-4 patches symmetrically attached on both sides was also considered (fig. 11). The $0^{\circ}$ plies are parallel to the $\mathrm{x}$ axis. The thicknesses of each composite ply and PZT-4 patch are 0.375 and $0.500 \mathrm{~mm}$, respectively, and the length aspect ratio was $L_{\xi} / L_{\eta}=2, L_{\eta}=140 \mathrm{~mm}$. The panel was clamped at the lower curved edge and free at all others, to resemble an untwisted cylindrical blade. The location of piezoelectric patches (shaded area) on each side and the finite element mesh are shown in figure 11. The surface terminals of each piezoceramic patch were assumed to be connected to an individual resistor, however, the values of the resistors were selected such that the specific resistance remained the same for all piezoceramic patches. The continuous electrodes were modeled using penalty equality constraints on the surface electric potential.

The predicted modal damping of the first five modes is shown in figure 12. Again the damping variation of each mode follows the familiar peak pattern as the resistance increases, yet the modal damping varies widely between various modes. Because of the finite size and continuous electrodes of the piezoelectric patches, their location and size become important parameters in connection with the respective mode shape. The present configuration seems to be more effective with flexural modes (modes 2, 4 and 5) while provides minimal damping for twisting modes ( 1 and 3). The lower damping values, compared to previous cases of idealized distributed piezoelectric layers. are attributed to the partial coverage of the surface by piezoelectric patches and the averaging of electric potential occurring on each piezoceramic due to the finite size of their continuous electrodes. Besides demonstrating the extreme capabilities of the developed methodology, the results show that the technique may yield substantial damping increases for select modes, provided that the shunting resistance, size, and location of the piezoelectric layers is properly designed. The value of the developed mechanics and finite element method in accomplishing such design tasks is apparent. 


\section{CONCLUSION REMARKS}

A formulation was described for predicting the damped dynamic characteristics of laminated composite shell structures with piezoelectric layers connected to distributed passive electric networks. The formulation includes multifield mechanics for curvilinear piezoelectric laminates having distributed passive electric components. Finite element based mechanics and an 8-node specialty shell element for predicting the modal damping. modal frequencies and damped response of piezoelectric shells were also formulated and encoded into research software.

Experimental and numerical studies illustrated the quality of the formulation and quantified the concept of passive piezoelectric damping on various structural configurations. The modal damping and frequencies of a composite heam with a variable resistor-piezoceramic element were measured and correlated with predicted results. Additional

correlations with exact in-plane solutions for plates and shells illustrated the fast convergence of the developed finite element. The modal damping and frequency of cylindrical composite blades with resistively shunted curved piezoelectric patches were also predicted. All analytical and experimental studies have shown that regardless of the structural configuration: (i) the concept of passive piezoelectric damping is feasible, and (ii) the damping can be easily tuned by changing the resistance value and reaches a peak at a specific resistance value which differs for each node. The shape of the structure seems to drastically affect the maximum damping value of each mode, with curvature effects being predominant. The finite size and location of piezoelectric elements also seem to affect the damping of each mode. Application of the technique on complex structural configurations may require careful design considerations. Overall, the results have illustrated the validity and effectiveness of the developed finite element formulation for analyzing and designing passively damped piezoelectric structures.

\section{REFERENCES}

1. Crawley, E.F., 1994, "Intelligent Structures for Aerospace: A Technology Overview and Assessment," AIAA Journal, 32:8, pp. 1689-1699.

2. Rao, S.S. and Sunar, M., 1994, "Piezoelectricity and Its Use in Disturbance Sensing and Control of Flexible Structures: A Survey," Applied Mechanics Reviews, 47:4, pp. 11.3-123.

3. Hagood N. W. and von Flotow A. H.. 1991. "Damping of Structural vibrations with piezoelectric materials and passive electrical networks." Joumal of Sound and Vibration, 146, pp. 243-268.

4. Law H.H.. Rossiter P.L., Simon G.P. and Koss L.L., 1996 "Characterization of Mechanical Vibration Damping by Piezoelectric Materials," Journal of Sound and Vibration, 197:4, pp. 489-513.

5. Davis C.L. and Lesieutre G.A., 1995, "A Modal Strain-Energy Approach to the Prediction of Resistively Shunted Piezoceramic Damping," Joumal of Sound and Vibration, 184:1, pp. 129-139.

6. Koshigoe S. and Murdock J.W.. 1993, "A Unified Analysis of Both Active and Passive Damping for a Plate with Piezoelectric Transducers." Journal of The Acoustical Society of America, 93:1, pp. 346-355.

7. Wang K.W., Lai J.S., Yu W.K., 1996, "An Energy Based Parametric Control Approach for Structural Vibration Suppression via Semi-Active Piezoelectric Networks," Journal of Vibration and Acoustics, 118:3, pp. 505-509.

8. Yarlagadda S.. Lesieutre G.A.. Yoshikawa S., Withnam J., 1996, "Resistively Shunted Piezocomposites for Passive Vibration Damping," AIAA-96-1291-CP, 37th AIAA/ASME/ASCE/AHS/ASC SDM Conference and Adaptive Structures Forum, Salt Lake City, UT, April 18-19, pp. 217-227.

9. Saravanos D.A. 1998, "Analysis of Damping in Composite Plates with Passive Piezoelectric-Resistor Elements." Joumal of Sound and Vibration, in review, 1998.

10. Saravanos D.A., 1997, "Coupled Mixed-Field Laminate Theory and Finite Element for Smart Piezoelectric Composite Shell Structures," AIAA Journal. Vol. 35:8. pp. 1327-1333. 
TABLE I--MECHANICAL PROPE R TIES

$\left(\varepsilon_{0}=8.8510^{12} \mathrm{farad} / \mathrm{m}\right.$. electric permittivity of air)

\begin{tabular}{|c|c|c|c|}
\hline & & Composite T300/934 & $\mathrm{PZT}-4$ \\
\hline Elastic properties & $\begin{array}{l}\mathrm{E}_{11}(\mathrm{GPa}) \\
\mathrm{E}_{22}(\mathrm{GPa}) \\
\mathrm{E}_{33}(\mathrm{GPa}) \\
\mathrm{G}_{23}(\mathrm{GPa}) \\
\mathrm{G}_{13}(\mathrm{GPa}) \\
\mathrm{G}_{12}(\mathrm{GPa}) \\
v_{12} \\
v_{13} \\
v_{13}\end{array}$ & $\begin{array}{c}132.4 \\
0.8 \\
10.8 \\
3.6 \\
5.6 \\
5.6 \\
0.24 \\
0.24 \\
0.49 \\
\end{array}$ & $\begin{array}{l}81.3 \\
81.3 \\
64.5 \\
25.6 \\
25.6 \\
30.6 \\
0.33 \\
0.43 \\
0.43 \\
\end{array}$ \\
\hline $\begin{array}{l}\text { Piezoelectric coefficients } \\
\left(10^{-12} \mathrm{~m} / \mathrm{V}\right)\end{array}$ & $\begin{array}{l}d_{31} \\
d_{32} \\
d_{2,1} \\
d_{14}\end{array}$ & $\begin{array}{l}0 \\
0 \\
0 \\
0\end{array}$ & $\begin{array}{c}-122 \\
-122 \\
495 \\
495 \\
\end{array}$ \\
\hline Electric permittivity & $\begin{array}{l}\varepsilon_{11} / \varepsilon_{11} \\
\varepsilon_{22} / \varepsilon_{11} \\
\varepsilon_{33} / \varepsilon_{1}\end{array}$ & $\begin{array}{l}3.5 \\
3.0 \\
3.0 \\
\end{array}$ & $\begin{array}{l}1475 \\
1475 \\
1300 \\
\end{array}$ \\
\hline Mass density $\rho\left(\mathrm{kg} / \mathrm{mi}^{3}\right)$ & & 1578 & 7600 \\
\hline
\end{tabular}

(a)

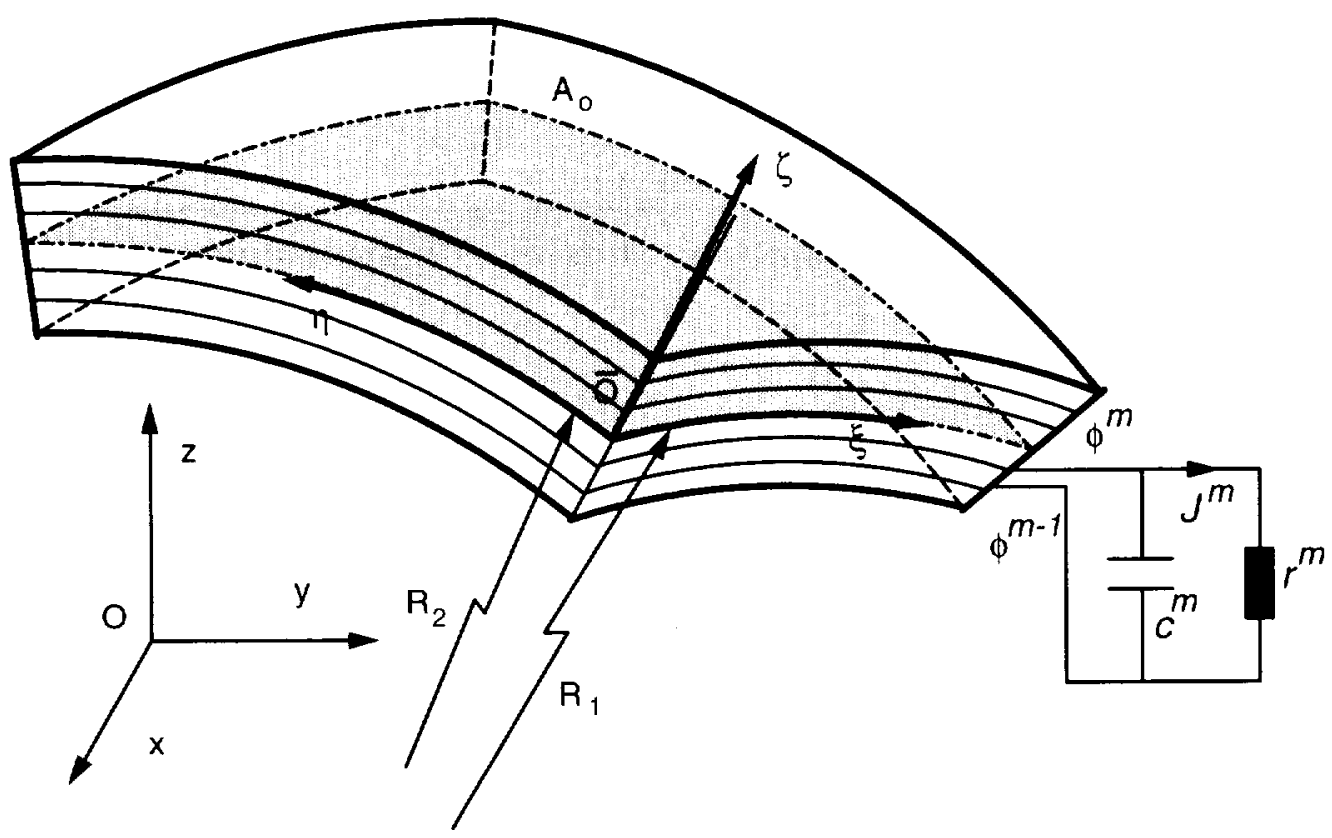

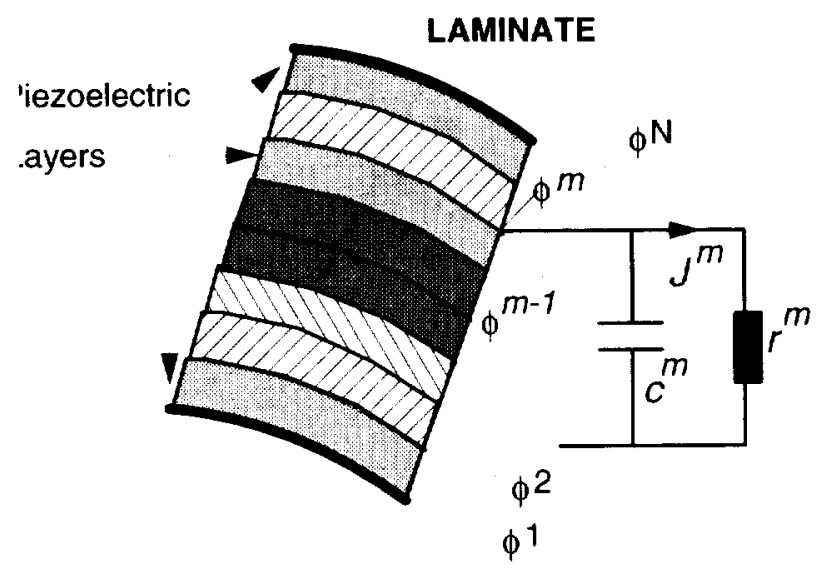

(b)

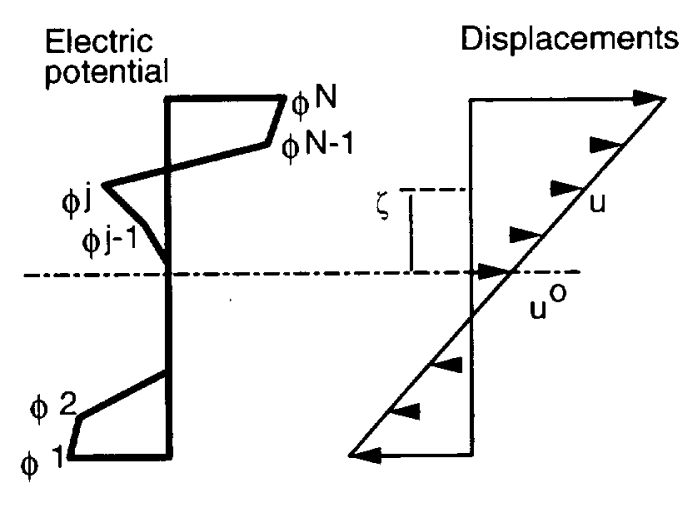

(c)

Figure 1.-Curvilinear piezoelectric laminate with embedded passive electric networks. (a) Geometry,

(b) through-thickness configuration, (c) assumed fields for electric potential and in-plane displacements 


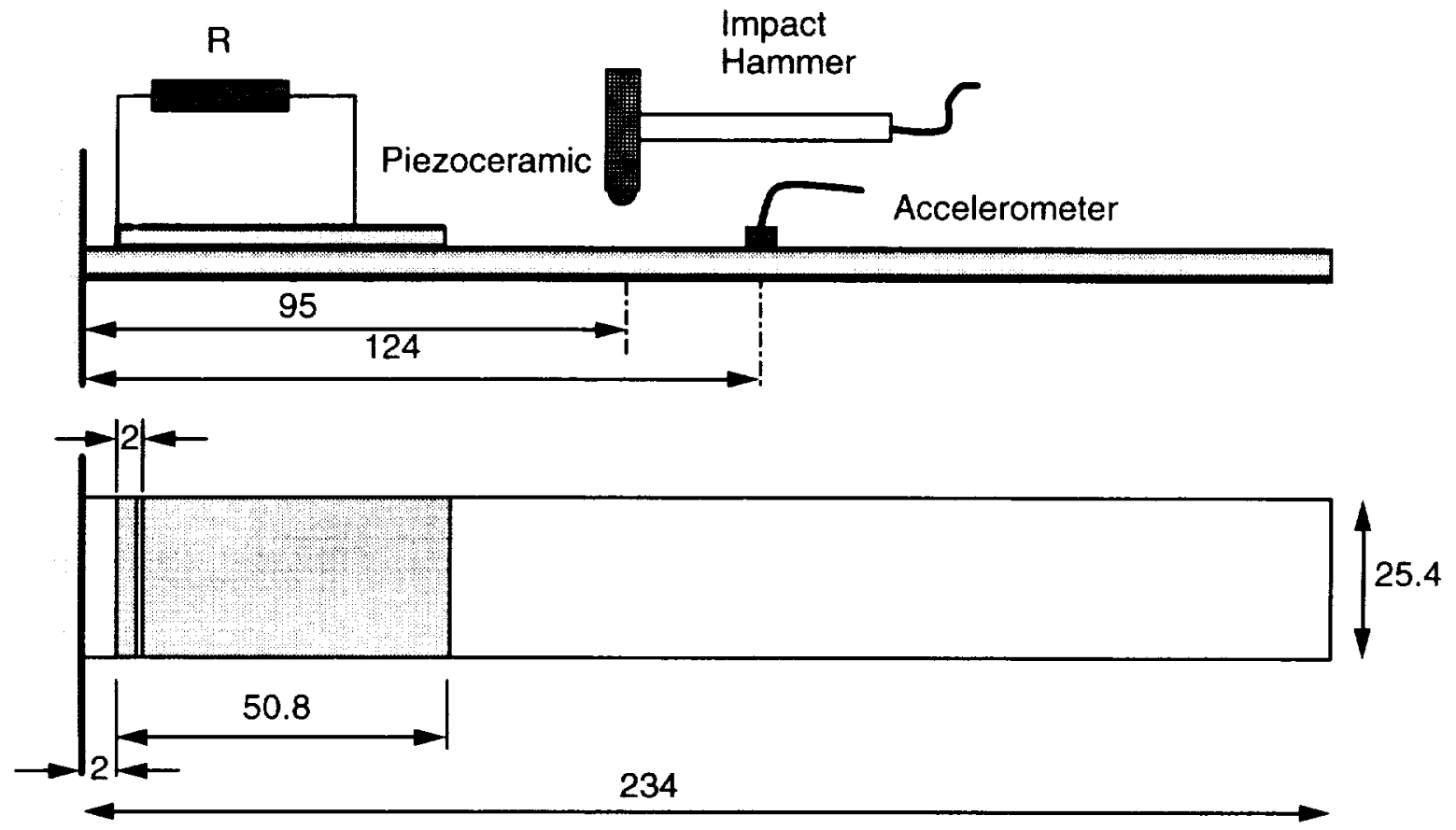

Figure 2. $-\left[0_{4} / 90_{4}\right]_{s}$ T300/934 cantilever beam with attached PZT-4 resistor patch. Side and top views. Dimensions in $\mathrm{mm}$.

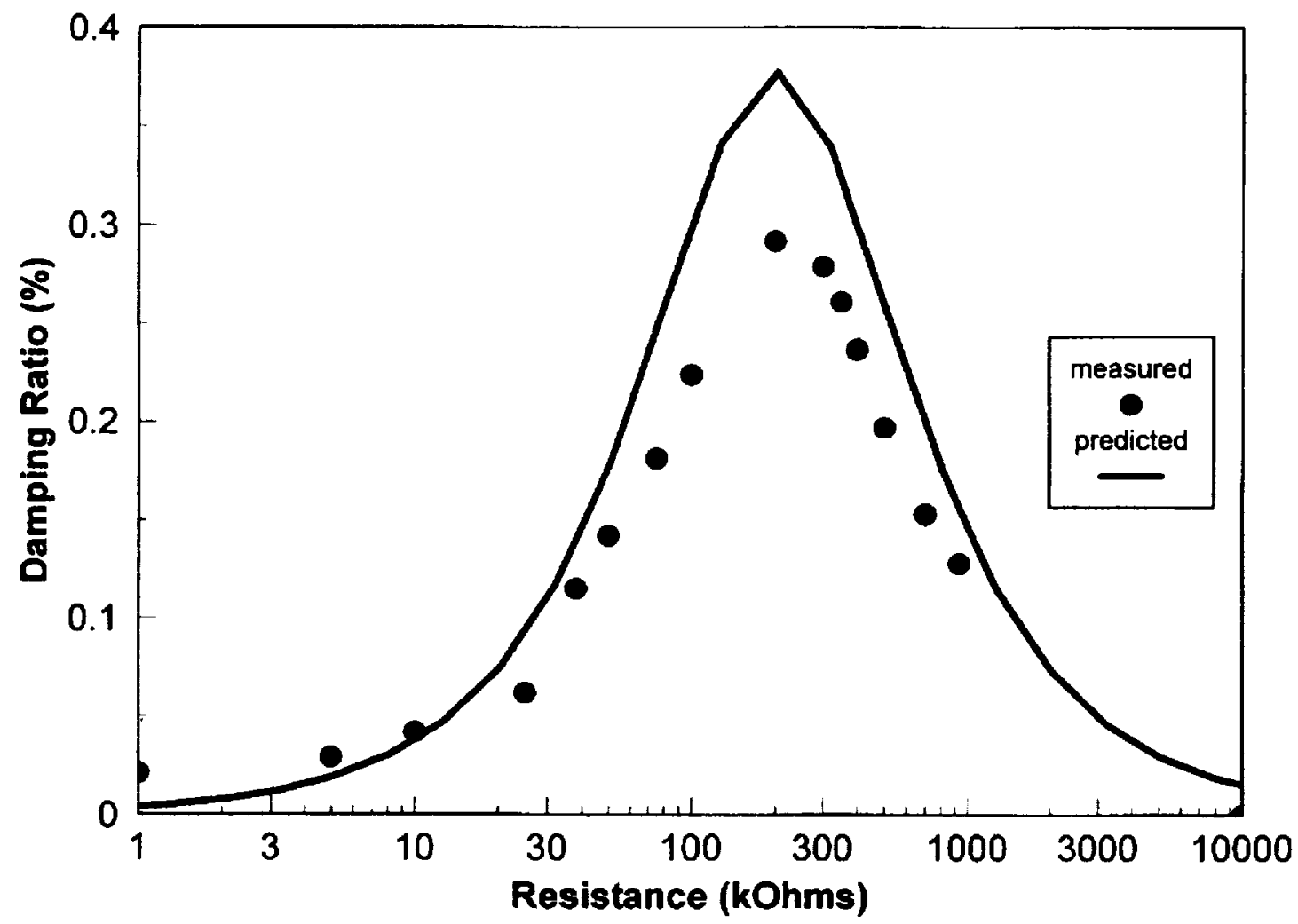

Figure 3.-Increase in the first mode damping of a $\left[0_{4} / 90_{4}\right]_{s}$ T300/934 beam for various resistance values 


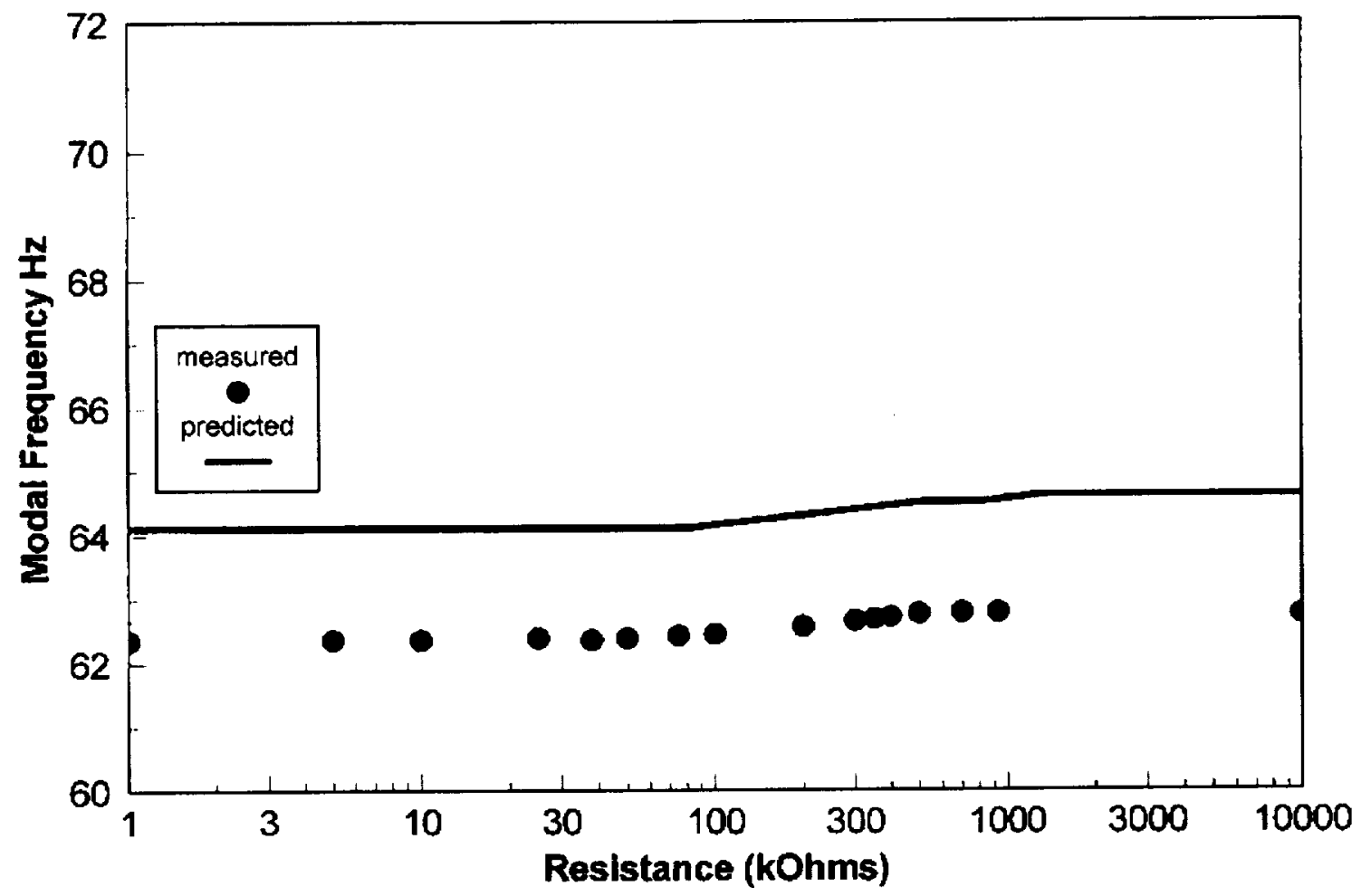

Figure 4.-Effect of resistance on the first modal frequency of $\left[0_{4} / 90_{4}\right]_{s}$ T300/934 beam. 

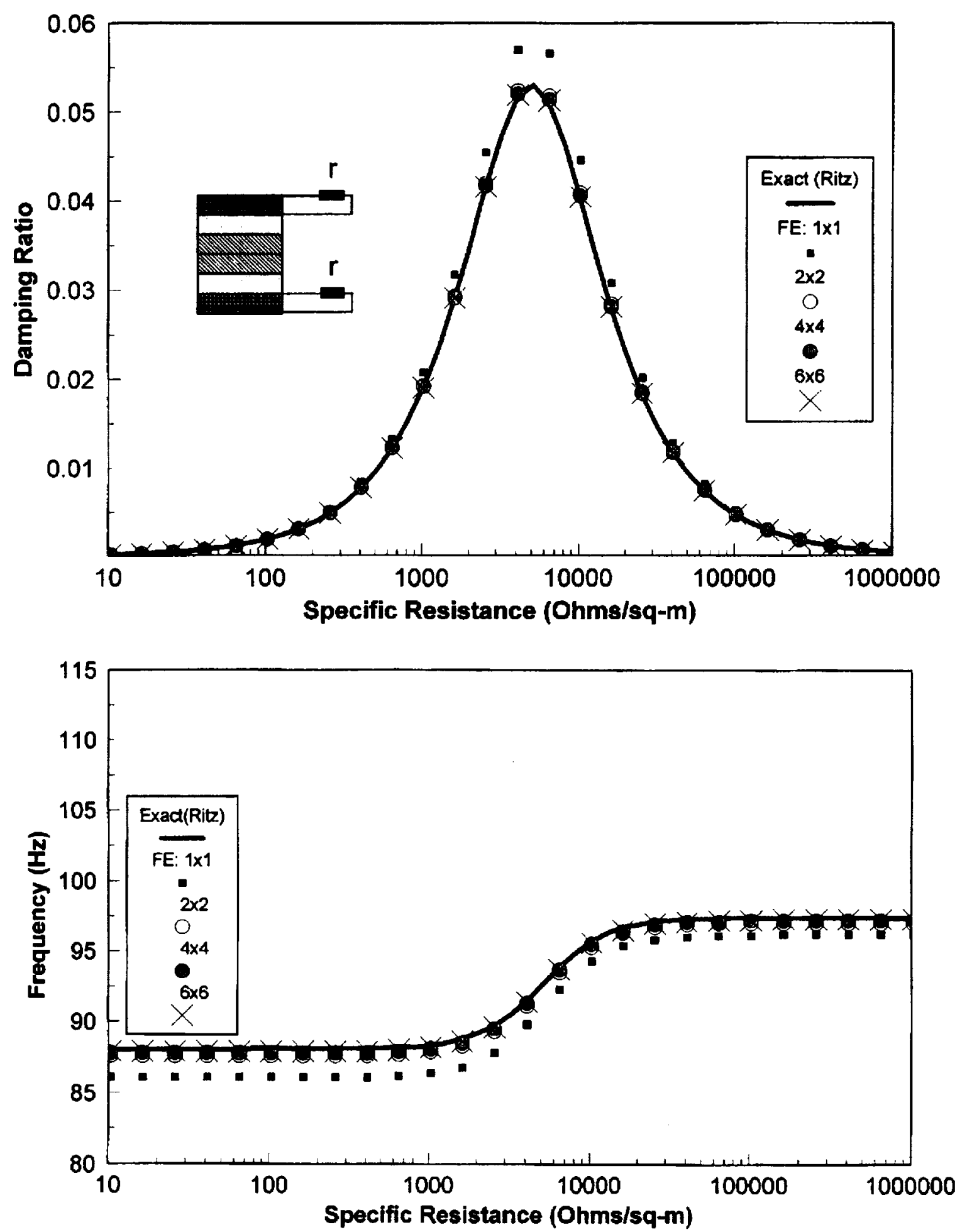

Figure 5.-Fundamental modal damping and frequency using various mesh densities for a $[\mathrm{p} / 0 / 90 / 90 / 0 / p]$ Graphite/Epoxy square plate with PZT-4 layers connected to distributed specific resistance $r$. 

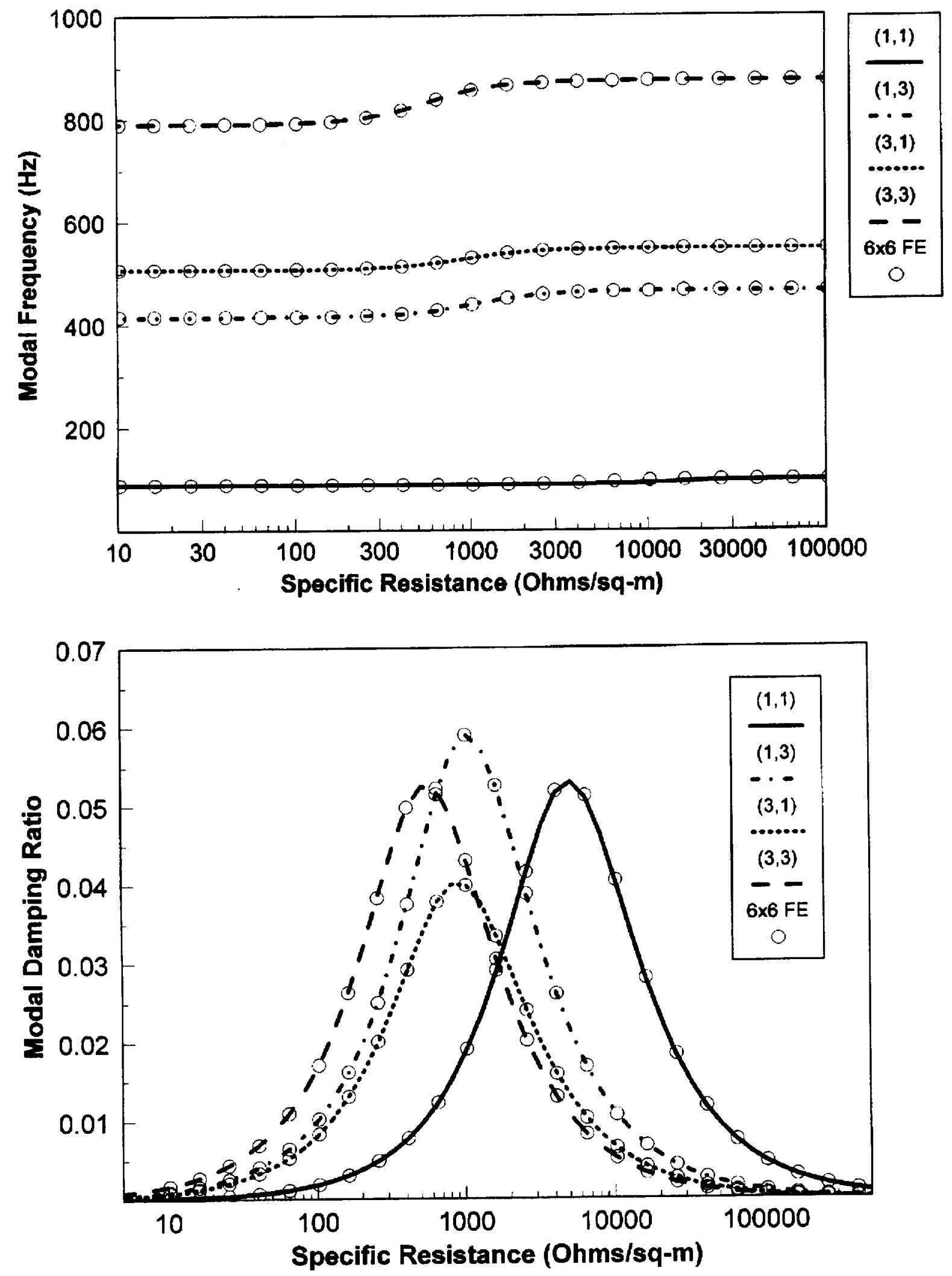

Figure 6.-Predicted damping and frequencies of the first 4 modes of a Graphite/Epoxy square plate with PZT-4 layers connected to distributed specific resistance $r$. 


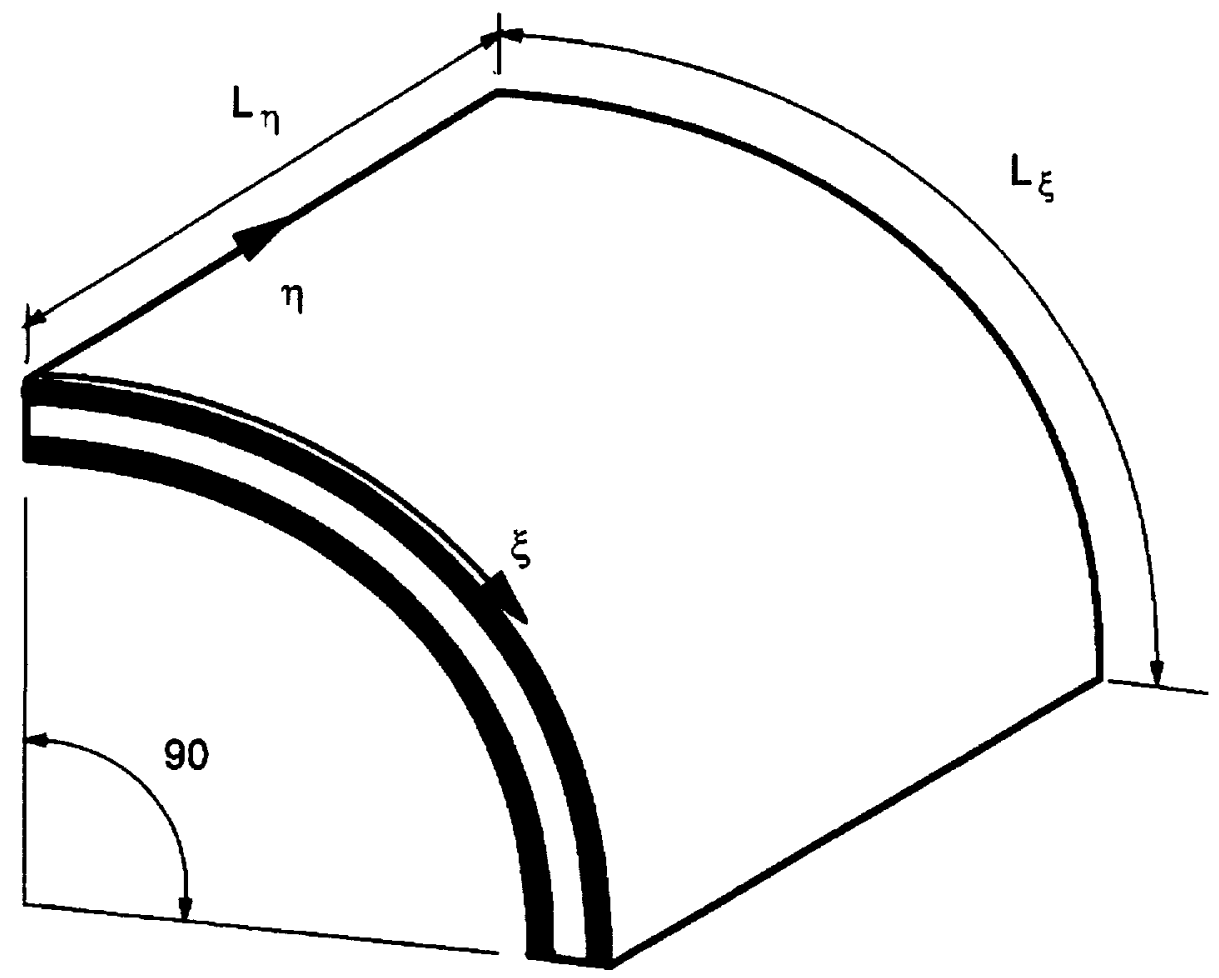

Figure 7.-Cylindrical [p/0/90/90/0/p] Graphite/Epoxy, PZT-4 quarter panel. 

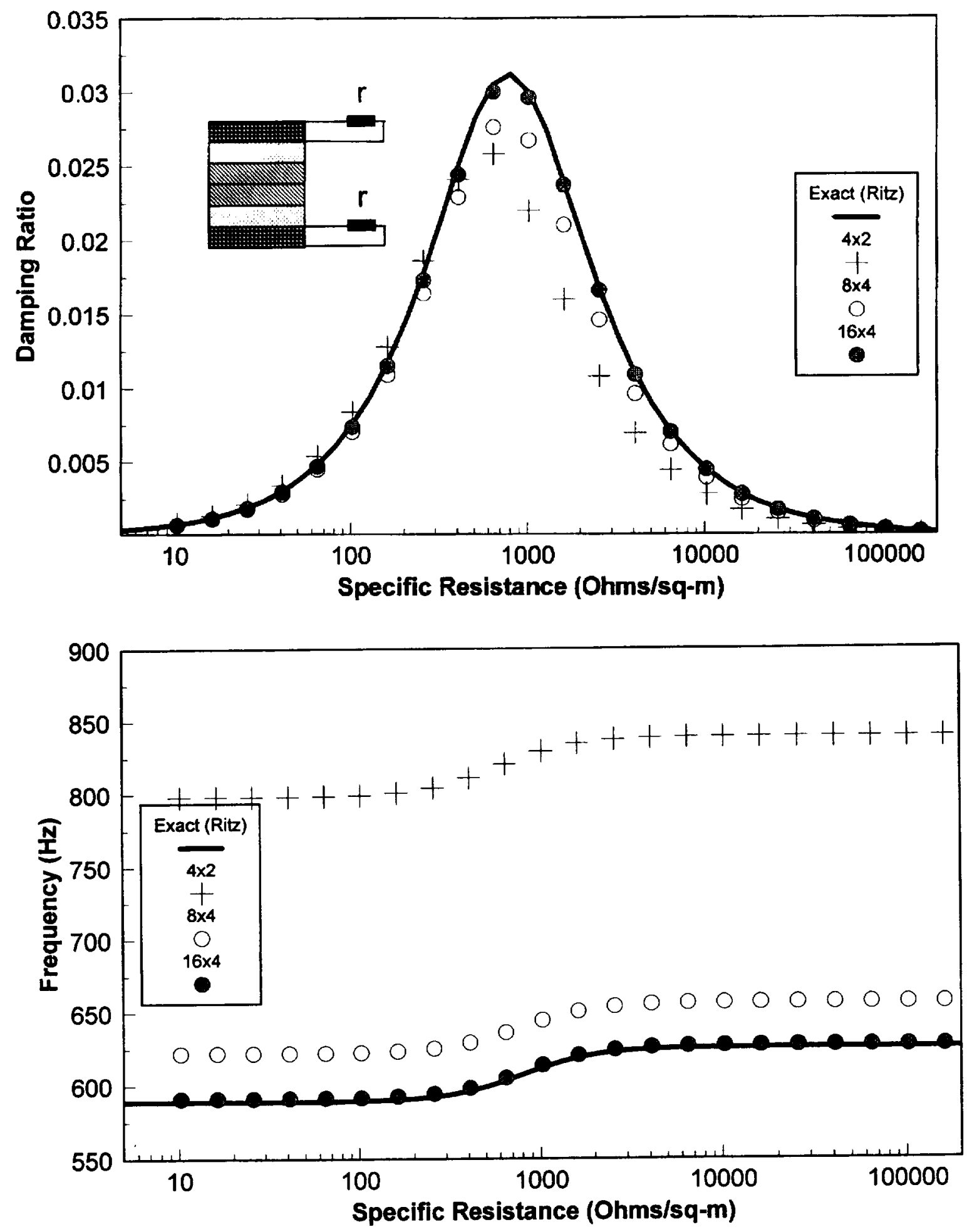

Figure 8.-Predicted damping and frequency of first frequency mode $(3,1)$ using various mesh densities for the $[\mathrm{p} / 0 / 90 / 90 / 0 / \mathrm{p}]$ Graphite/Epoxy cylindrical quarter panel (Fig. 7) with distributed specific resistance $r$ connected to each PZT-4 layer. 

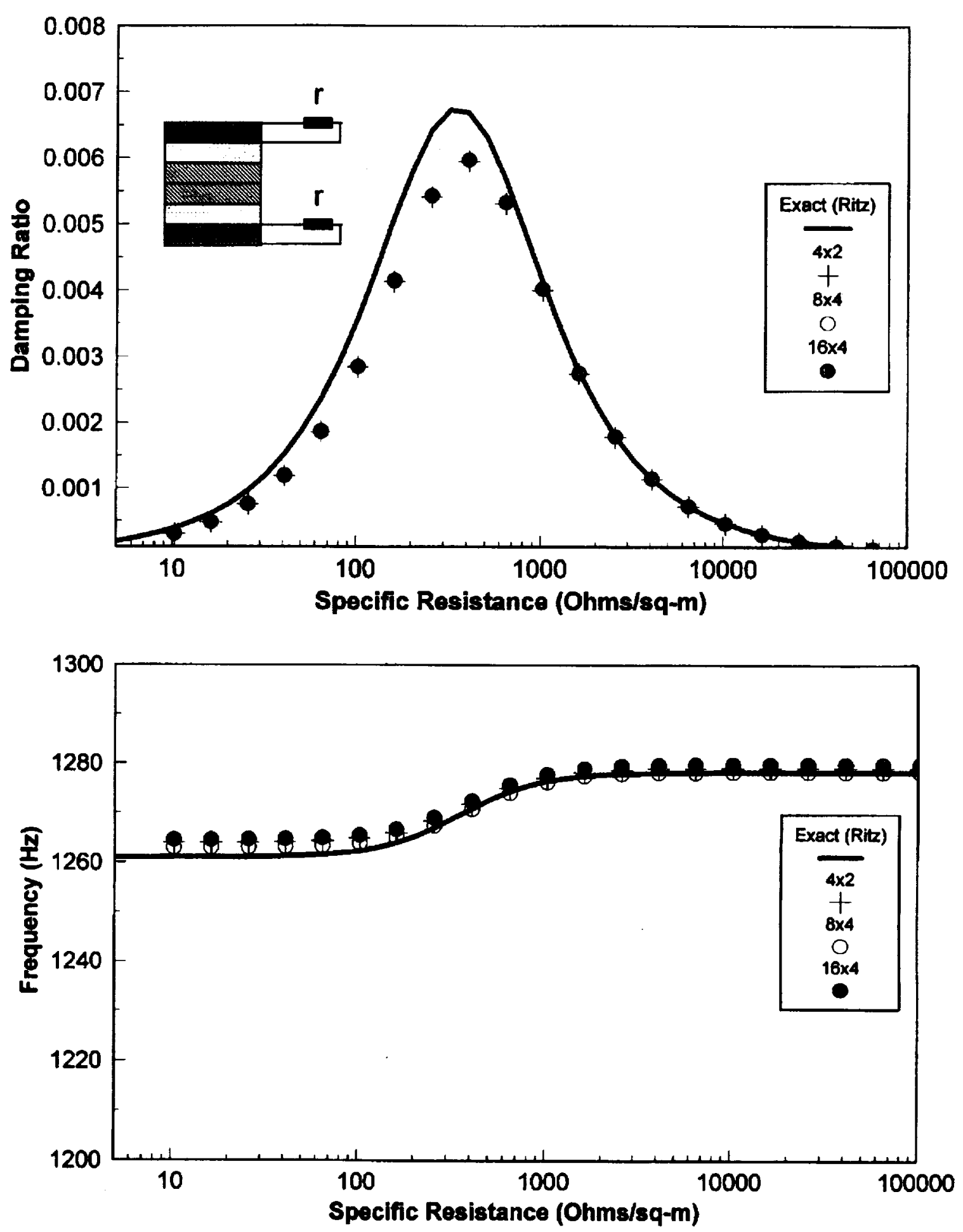

Figure 9.-Predicted damping and frequency of mode $(1,1)$ using various mesh densities for the $[\mathrm{p} / 0 / 90 / 90 / 0 / \mathrm{p}]$ Graphite/Epoxy cylindrical quarter panel (Fig. 7) with distributed specific resistance $r$ connected to each PZT-4 layer. 


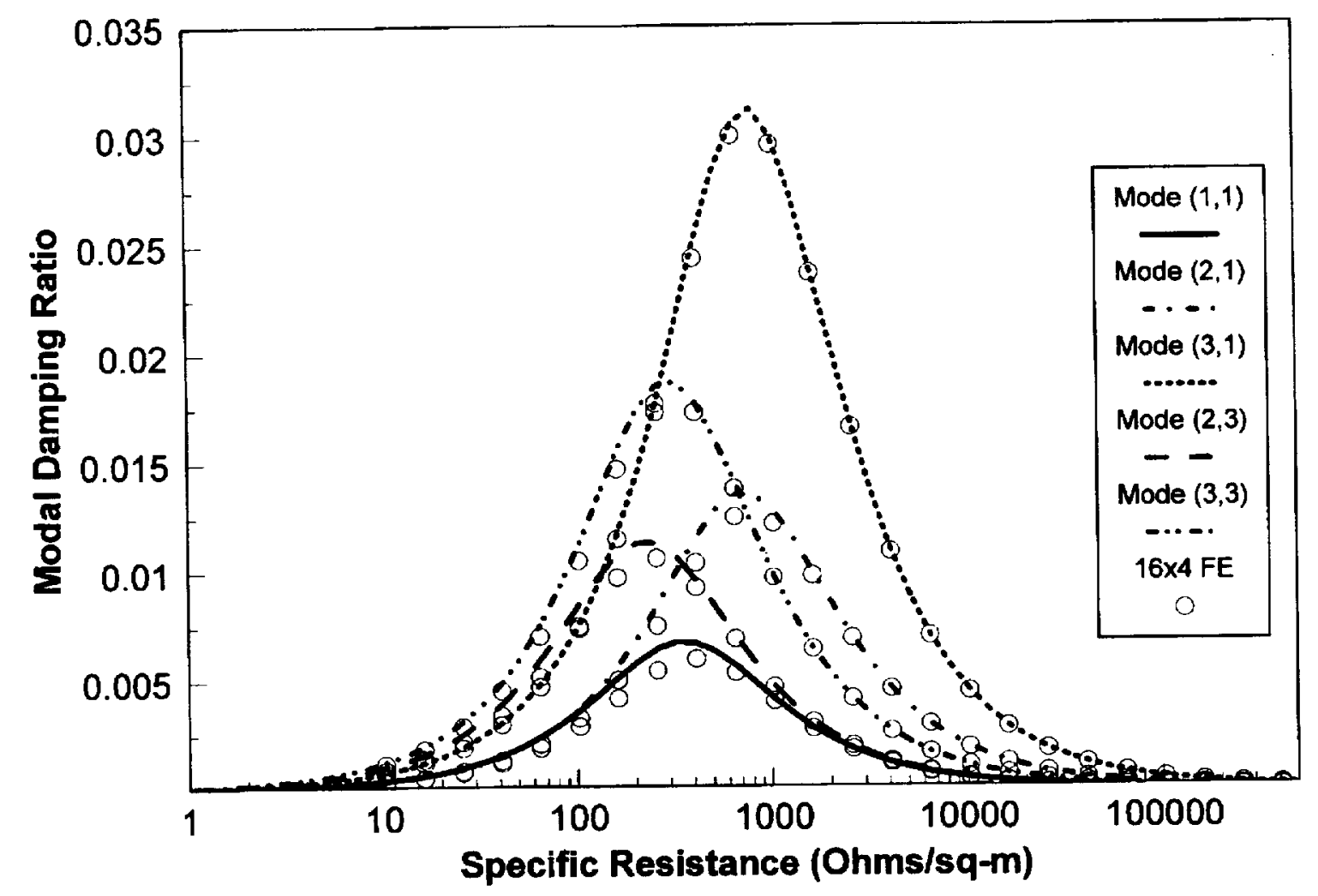

Figure 10.-Damping of various mode shapes for the $[\mathrm{p} / 0 / 90 / 90 / 0 / p]$ Graphite/Epoxy cylindrical quarter panel (Fig. 7) with distributed specific resistance $r$ connected to each PZT-4 layer. 


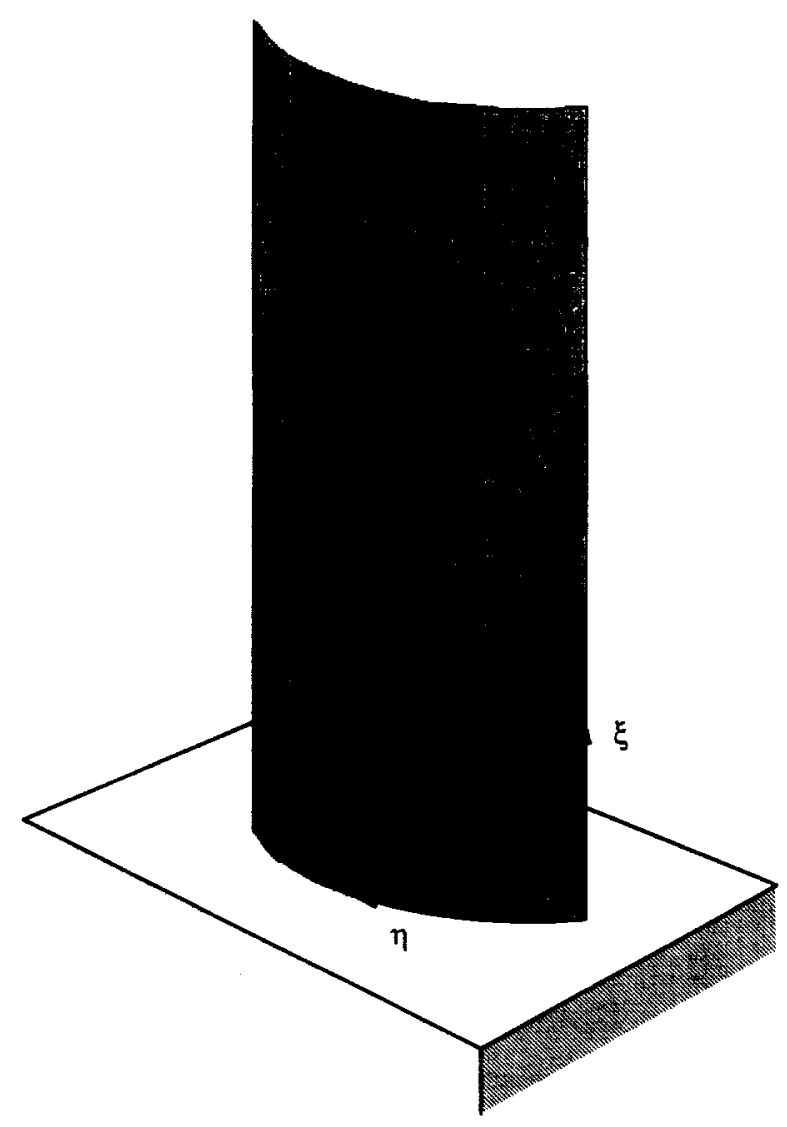

Figure 11. Cylindrical [0/90/45/-45] $\mathrm{s}$ Gr/Epoxy panel with symmetrically attached resistively shunted curved PZT-4 patches (shown as shaded areas) on both sides. 
Public reporting burden tor this collection of information is estimated to average 1 hour per response, including the time for reviewing instructions. searching existing data sources, gathering and maintaining the data needed, and completing and reviewing the collection of information. Send comments regarding this burden estimate or any other aspect of this Davis Highway. Suite 1204, Arlington, VA 22202-4302, and to the Oftice of Management and Budget. Paperwork Reduction Project (0704-01B8), Washington, DC 20503
1. AGENCY USE ONLY (Leave blank) 2. REPORT DATE
March 1999 3. REPORT TYPE AND DATES COVERED
Final Contractor Report

4. TITLE AND SUBTITLE

Passively Damped Laminated Piezoelectric Shell Structures

With Integrated Electric Networks

6. AUTHOR(S)

Dimitris A. Saravanos

7. PERFORMING ORGANIZATION NAME(S) AND ADDRESS(ES)

Ohio Aerospace Institute

22800 Cedar Point Road

Cleveland, Ohio 44142

WU-523-21-13-00

NCC $3-455$

9. SPONSORING/MONITORING AGENCY NAME(S) AND ADDRESS(ES)

National Aeronautics and Space Administration

John H. Glenn Research Center at Lewis Field

PERFORMING ORGANIZATION REPORT NUMBER

Cleveland, Ohio 44135-3191

NASA CR-1999-208871

11. SUPPLEMENTARY NOTES

Project Manager, Dale Hopkins, Structures and Acoustics Division, organization code 5930, (216) 43.3-3260.

12a. DISTRIBUTIONIAVAILABILITY STATEMENT

Unclassified - Unlimited

Subject Category: 39
Distribution: Nonstandard
10. SPONSORINGMONITORING AGENCY REPORT NUMBER

This publication is available from the NASA Center for AeroSpace Information, (301) $621-0390$.

13. ABSTRACT (Maximum 200 words)

Multi-field mechanics are presented for curvilinear piezoelectric laminates interfaced with distributed passive electric components. The equations of motion for laminated piezoelectric shell structures with embedded passive electric networks are directly formulated and solved using a finite element methodology. The modal damping and frequencies of the piezoelectric shell are calculated from the poles of the system. Experimental and numerical results are presented for the modal damping and frequency of composite beams with a resistively shunted piezoceramic patch. The modal damping and frequency of plates, cylindrical shells and cylindrical composite blades with piezoelectric-resistor layers are predicted. Both analytical and experimental studies illustrate a unique dependence of modal damping and frequencies on the shunting resistance and show the effect of structural shape and curvature on piezoelectric damping.

14. SUBJECT TERMS

Damping; Composite structures; Smart structures; Shells; Piezoelectric ceramics; Finite element method

17. SECURITY CLASSIFICATION OF REPORT

Unclassified
18. SECURITY CLASSIFICATION OF THIS PAGE Unclassified
19. SECURITY CLASSIFICATION OF ABSTRACT

Unclassified
15. NUMBER OF PAGES 25

16. PRICE CODE

$\mathrm{A03}$

20. LIMITATION OF ABSTRACT 


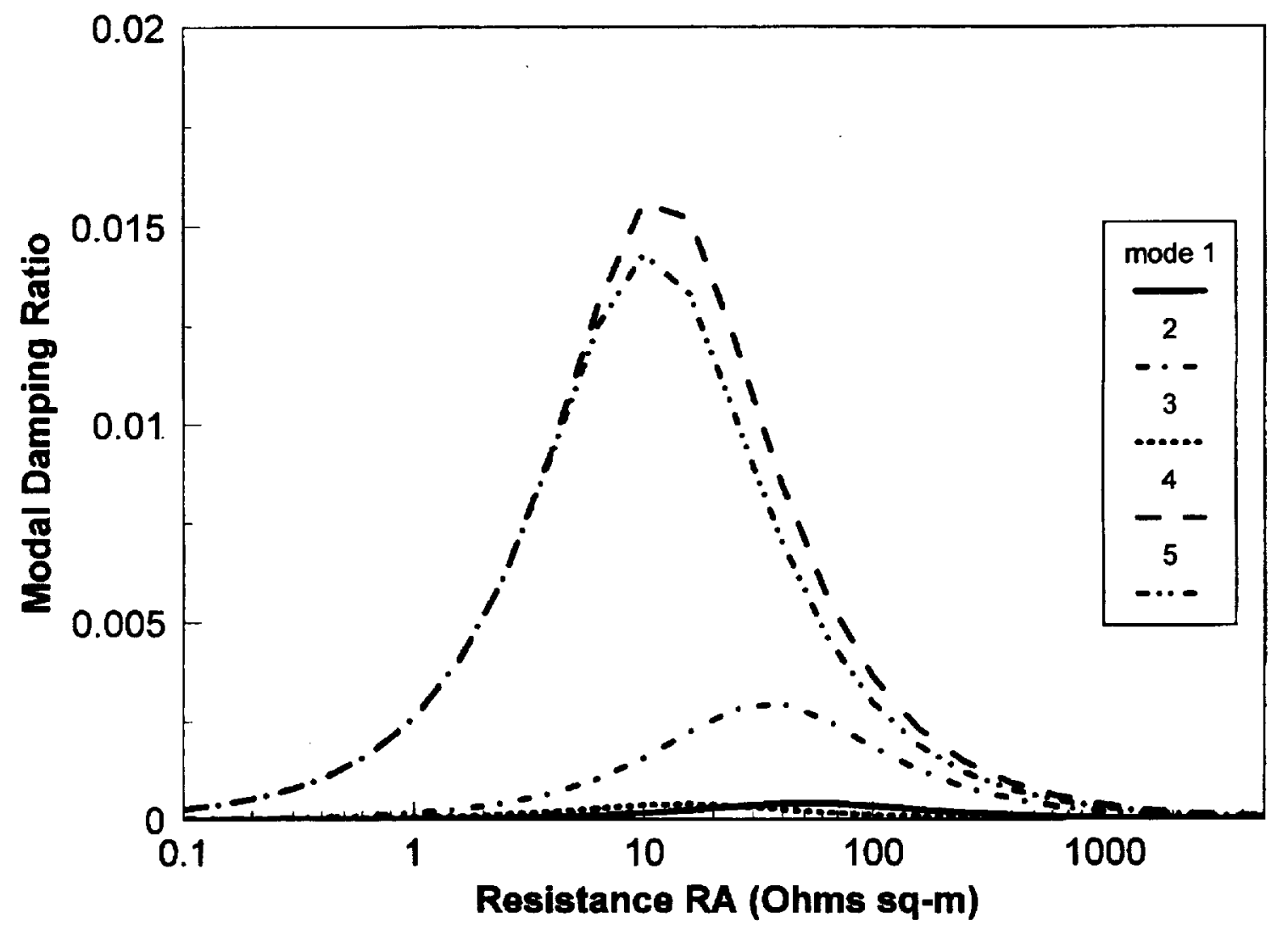

Figure 12.-Damping predictions for the first 5 modes of the cantilever cylindrical $[0 / 90 / 45 /-45]_{S}$ Gr/Epoxy panel. 